Technological University Dublin

ARROW@TU Dublin

2008-09-01

\title{
Equi-Biaxial Fatigue of Elastomers: the Effect of Oil Swelling on Fatigue Life
}

\author{
Stephen Jerrams \\ Technological University Dublin, stephen.jerrams@tudublin.ie \\ John Hanley \\ Technological University Dublin, john.hanley@tudublin.ie \\ Niall Murphy \\ Technological University Dublin, niall.murphy@tudublin.ie
}

See next page for additional authors

Follow this and additional works at: https://arrow.tudublin.ie/cerart

Part of the Polymer and Organic Materials Commons

\section{Recommended Citation}

Jerrams, S., Hanley, J., Murphy, N. \& Hassan, A. (2008) Equi-Biaxial Fatigue of Elastomers: the Effect of Oil Swelling on Fatigue Life. Rubber Chemistry and Technology, Vol 81, Iss 4, P 638-649, September/October 2008. doi:10.5254/1.3548224

This Article is brought to you for free and open access by the Centre for Elastomer Research at ARROW@TU Dublin. It has been accepted for inclusion in Articles by an authorized administrator of ARROW@TU Dublin. For more information, please contact arrow.admin@tudublin.ie, aisling.coyne@tudublin.ie,gerard.connolly@tudublin.ie. Funder: Enterprise Ireland

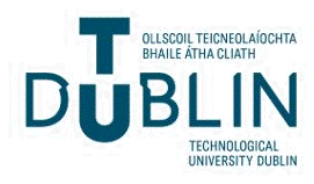


Authors

Stephen Jerrams, John Hanley, Niall Murphy, and Ali Hassan

This article is available at ARROW@TU Dublin: https://arrow.tudublin.ie/cerart/6 
9-1-2008

\section{Equi-biaxial fatigue of elastomers: The effect of oil swelling on fatigue life}

Stephen J. Jerrams Dr

Dublin Institute of Technology, stephen.jerrams@dit.ie

John Hanley Dr

Dublin Institute of Technology

Niall Murphy Dr

Dublin Institute of Technology

Hassan Ali Dr 


\title{
EQUI-BIAXIAL FATIGUE OF ELASTOMERS: THE EFFECT OF OIL SWELLING ON FATIGUE LIFE
}

\author{
STEVe JerRAMS* \\ Directorate of RESEARCh AND ENTERPRISE, Dublin INSTITUTE of TECHNOLOGY, 143-149 RathMinES \\ DUBLIN 6, IRELAND \\ John Hanley, Niall Murphy \\ School of Manufacturing and Design Engineering, Dublin Institute of Technology, Bolton Street \\ DUBLIN 1, IRELAND \\ HASSAN ALI \\ School of Chemical and Pharmaceutical Sciences, Dublin Institute of Technology \\ Kevin STREET, DuBLIN 2, IRELAND
}

\begin{abstract}
The effect of oil swelling on the fatigue life of ethylene propylene diene monomer rubber (EPDM) has been studied under conditions of equi-biaxial cycing using dynamic bubble inflation. Specimens were subjected to varying degrees of swelling in reference mineral oils and fatigued at constant engineering stress amplitudes. The reference oils used for swelling the EPDM had known aniline points, allowing the rubber-oil compatibility to be determined. The inflation fluid for fatigue testing was selected with a solubility parameter that would produce a desired level of incompatibility with the test specimens, thereby limiting the amount of additional swelling during cycling. Wöhler (S-N) plots were generated for dry and swollen specimens and the changes in complex elastic modulus $\mathrm{E}^{*}$ and dynamic stored energy were analyzed. Specimen fractures were anaiyzed using scanning electron microscopy. The fractures in the swollen samples show that the failure surfaces flowed more readily over each other than did those of the dryer specimens.
\end{abstract}

\section{INTRODUCTION}

Most rubber components fail in fatigue and consequently determining elastomeric component fatigue life has acquired greater interest to materials scientists in recent years. Fatigue testing to date has generated results using equipment which loaded the specimens in uniaxial tension, combined tension and torsion or in shear. While these methods provide much useful insight into the fatigue behavior of elastomers, they do not describe the full spectrum of elastomeric material behavior under cyclic loading. ${ }^{1}$

Dynamic bubble inflation is capable of loading test-pieces in equi-biaxial tension for any stress or strain amplitude to record the total cycles to failure. This method allows specimens to be fatigued to failure equi-biaxially and facilitates completion of the characterization of fatigue life for all loading cases for a particular elastomer. In this case, the characterization of the dynamic properties of EPDM is further expiored to establish the effect of swelling on the equi-biaxial properties of initially dry elastomers.

A fundamental question posed is whether oil swelling agents affect the fatigue behavior of the rubber, where it is subjected to prior treatment before loading. The effect of swelling on elastomers has been studied comprehensively under static loading, where the degree of cross-linking of the material and hence its modulus was found to be related to swelling potential by the FloryRehner equation. ${ }^{2}$

There have been fewer investigations of elastomeric dynamic behavior, especially where oil swelling is considered. ${ }^{3-6}$

By undertaking these tests, it was anticipated that the resultant damage caused by swelling

* Corresponding author. Ph: +353 1 4027537; Fax: +353 1 4023393; email: stephen.jerrams@dit.ie 
and the consequent influence that swelling has on fatigue resistance could be determined for the equi-biaxial load case.

\section{OBJECTIVE}

To investigate the influence of swelling in equi-biaxial fatigue, it was proposed to test three different EPDM specimen sets using dynamic bubble inflation between pre-set maximum and zero minimum engineering stress limits. The test specimens were prepared in the following manner:

- Dry specimens, fatigued to failure. Test-pieces were not pre-treated and silicone based oil was selected as the inflation fluid for the tests to minimize any swelling effects.

- Prior to fatigue testing, specimens were swollen in two different ASTM reference oils, IRM 902 and IRM 903. Test-pieces were not conditioned before fatigue testing. Following removal from the swelling medium, test-pieces were equi-biaxially tested to failure in fatigue, again using silicone based oil to minimize additional swelling effects during the dynamic tests.

Consequently, the aims of this investigation were as follows:

1) To determine if fatigue strength reductions due to swelling in rubber specimens loaded equi-biaxially were consistent with strength reductions in samples subjected to uniaxial tests to failure.

2) To establish equi-biaxial Wöhler (S-N) curves for a range of rubbers swollen in different media in tests conducted at constant stress amplitudes.

3) To establish relationships between cycles to failure and dynamic modulus and stored energy.

4) To offer predictors of fatigue life for dry/swollen specimens subjected to equi-biaxial fatigue.

\section{TEST METHODOLOGY}

\section{MATERIALS AND SPECIMENS}

EPDM rubber of 70 Shore A hardness, cross-linked with sulphur and containing low activity carbon black was chosen for this investigation. Specimens had a $50 \mathrm{~mm}$ original diameter and $2 \mathrm{~mm}$ original thickness. For the bubble inflation tests, these samples were clamped and dynamically inflated and deflated through a $35 \mathrm{~mm}$ diameter orifice. Prepared specimens had a pattern of dots applied to their surface. The deformation of this pattern during inflation and deflation is recorded by an optical system, with each image captured allowing correlation to a specific engineering stress value at the bubble pole.

\section{SWELLING EXPERIMENTS}

All rubber will swell to some extent in oil, but the degree of swelling can be estimated for a particular oil-rubber combination if the solubility parameters $\delta$ for both components of the mixture are known. If the square root of the difference between the solubility parameters of the rubber and the oil is less than 1, as shown in Equation (1), then the rubber will swell appreciably in that oil. ${ }^{7}$

$$
\left(\delta_{1}-\delta_{2}\right)^{\frac{1}{2}}<1
$$

There can be difficulties in accurately determining the solubility parameter for a fluid when it consists of two or more fractions. However, it has been found from experimentation that that 
the solubility parameter for a hydraulic fluid may be estimated from other known physical properties which are readily available, such as the aniline point of the oil. The relationship between the solubility parameter and the aniline point of the oils being tested can be plotted as an empirical linear relationship. ${ }^{8}$

To control the degree of oil swell in rubbers it is necessary to use hydraulic fluids where the properties have been determined and which can consequently be used as a reference. From the ASTM standards for rubber-liquid compatibility, the reference oil IRM 903 is the most appropriate choice of oil for high swelling of EPDM. ${ }^{9}$ Its aniline point has been determined and can be compared with the solubility parameter for the test material to allow rubber-liquid compatibility to be gauged. Moreover, it is generally comparable with typical hydraulic oils in terms of liquid properties. By using reference oil, IRM 902, which imparts medium swell effects, the influence of variation of oil solubility on rubber properties may also be investigated. The properties of the liquids used are summarized in Table I.

TABLE I

REFERENCE OIL PROPERTIES

\begin{tabular}{lcc}
\hline & IRM 902 & IRM 903 \\
\hline Boiling Point & $>316^{\circ} \mathrm{C}$ & $>249^{\circ} \mathrm{C}$ \\
\hline Vapor Pressure & $<0.001 \mathrm{~mm} \mathrm{Hg} @ 20^{\circ} \mathrm{C}$ & $<0.001 \mathrm{~mm} \mathrm{Hg} @ 20^{\circ} \mathrm{C}$ \\
\hline Specific Gravity & $0.93($ Water $=1)$ & $0.92($ Water $=1)$ \\
\hline Molecular Weight & 460 gmol-1 & 319 gmol- 1 \\
\hline Viscosity & $20.48 \mathrm{cST} @ 99^{\circ} \mathrm{C}$ & $33.3 \mathrm{cST} \mathrm{@} \mathrm{99}{ }^{\circ} \mathrm{C}$ \\
\hline Aniline Point & $92.7^{\circ} \mathrm{C}$ & $70.6^{\circ} \mathrm{C}$ \\
\hline
\end{tabular}

Swelling experiments were carried out by immersing the specimens in reference oil at 100 ${ }^{\circ} \mathrm{C}$ for one hour. The specimens were removed from the hot oil and cooled in oil at ambient temperature for a short period, before being wiped dry and weighed. An average swelling ratio was calculated for the samples, where the swelling ratio $Q$ was expressed as,

$$
Q=\frac{W_{s}}{W_{d}}
$$

where $W_{s}$ is the weight of the swollen elastomer sample and $W_{d}$ is the weight of dry elastomer before swelling. ${ }^{9} \mathrm{~A}$ swelling ratio of 1.10 (10\% increase in mass) was calculated for the EPDM swollen in IRM 903 and a ratio of 1.042 (4.2\% increase in mass) for the EPDM swollen in IRM 902.

The three different EPDM specimen sets (Dry, 10\% Swell, $4.2 \%$ Swell) were then tested in equi-biaxial fatigue, between pre-set maximum and zero minimum engineering stress limits. An inflation fluid (silicone based oil) was chosen that would minimize any additional swelling effects during dynamic loading.

\section{TEST METHOD}

The dynamic bubble inflation test rig (DYNAMET) provides a method of determining the mechanical properties of elastomers in equi-biaxial deformation under fatigue conditions. ${ }^{10-12}$ The test apparatus consists of a hydraulic inflation/deflation system and a strain measurement system. The strain measurement is based on a stereo vision system, with two charge coupled 
device (CCD) cameras connected to a PC. The cameras are mounted over the specimen and the output from each camera is combined to allow 3-dimensional data to be determined. A calibration routine is required to ensure that the co-ordinates measured by each camera can be related to each other. The raw measured $\mathrm{X}, \mathrm{Y}, \mathrm{Z}$ data is output in pixel coordinates and this data must be combined for each camera and rotated, translated and scaled using constants generated as part of the calibration process. Once scaled into millimeters, the X, Y, Z data is used for two purposes. First, the radius of the bubble is calculated using a least squares fit based on an elliptical contour function through the $\mathrm{X}, \mathrm{Z}$ co-ordinates for a particular frame. Second, the $\mathrm{X}$ data for a particular frame is combined with the corresponding radial data to calculate the circumferential spacing of the markings on the surface of the test-piece. Pressure readings are synchronized with the cameras during the image capture sequences, by taking a pressure measurement every time an image capturing trigger signal is output to the cameras.

The DYNAMET system is shown in Figure 1, where the displacement of specimen markings for a number of inflation/deflation cycles is shown.

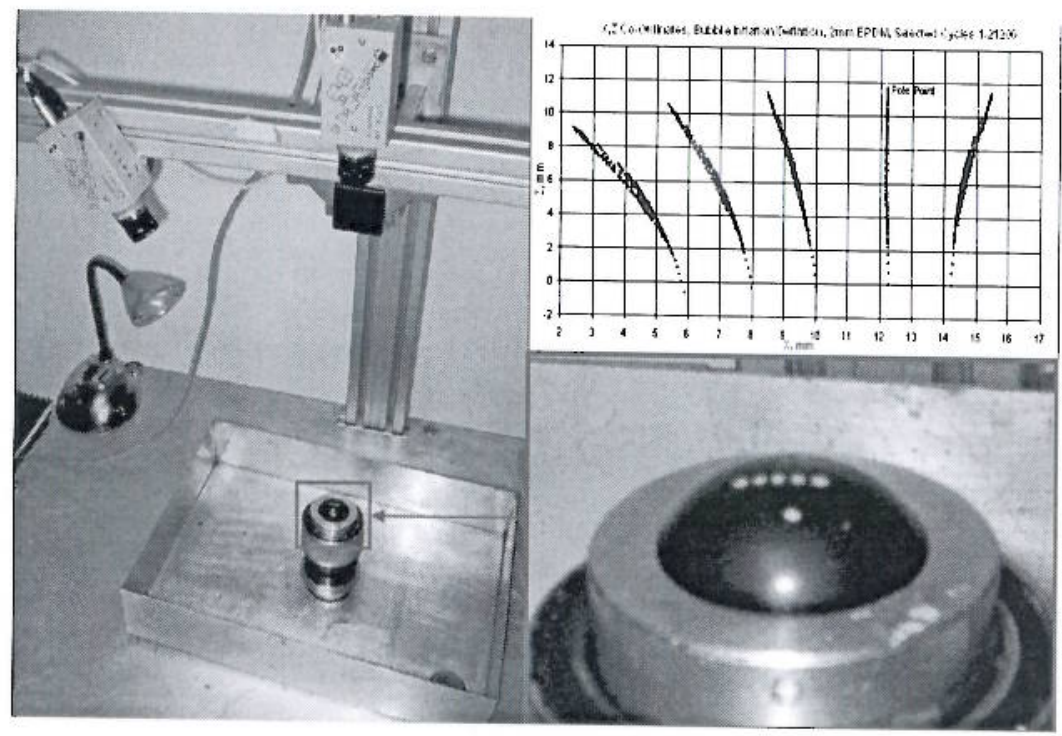

FIG. 1.- DYNAMET Bubble Inflation Tester.

The stress-strain relation during bubble inflation is assumed to comply with membrane theory where, from the measurement of pressure $\mathrm{P}$ and the radius of curvature $\mathrm{R}$, the equation for stress at the pole can be determined using Equation (3).

$$
\sigma=\frac{P R}{2 t}
$$

Local stretch ratios at the pole can be determined using Equation (4):

$$
\lambda=\left(\left(x_{\text {cir }}-x_{\text {orig }}\right) / x_{\text {orig }}\right)+1
$$

Where $\lambda$ is the principal stretch ratio, $x_{\text {cir }}$ is the circumferential point spacing at the bubble pole and $x_{\text {orig }}$ is the original point spacing. ${ }^{\text {cir }}$ 


\section{RESULTS}

\section{FATIGUE TESTS}

All fatigue tests were carried out at frequencies of $1 \mathrm{~Hz}$. This minimized any potential sample degradation due to heat build-up during cyclic loading. ${ }^{14}$ To maintain a constant peak engineering stress in a cycle for each and every cycle, the pressure set-point was adjusted continually throughout a test. By using this method of control, practical S-N curves could be obtained to compare the fatigue lives of the dry versus the swollen rubber. Figure 2 shows hysteresis curves for four cycles in a fatigue test where constant stress control is used.

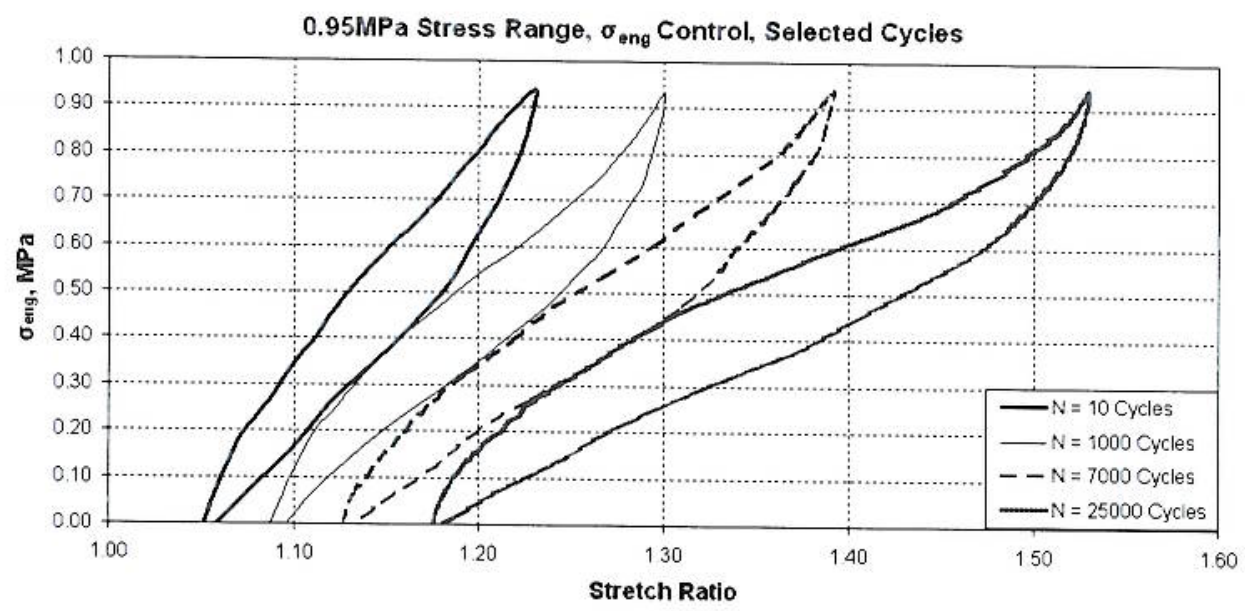

FIG. 2.- Hysteresis curves for cycles $\mathrm{N}=10,1000,7000,25000$.

All fatigue tests were carried out with a zero minimum stress. The plot of stress amplitude versus cycles to failure for all three specimen sets is shown in Figure 3.

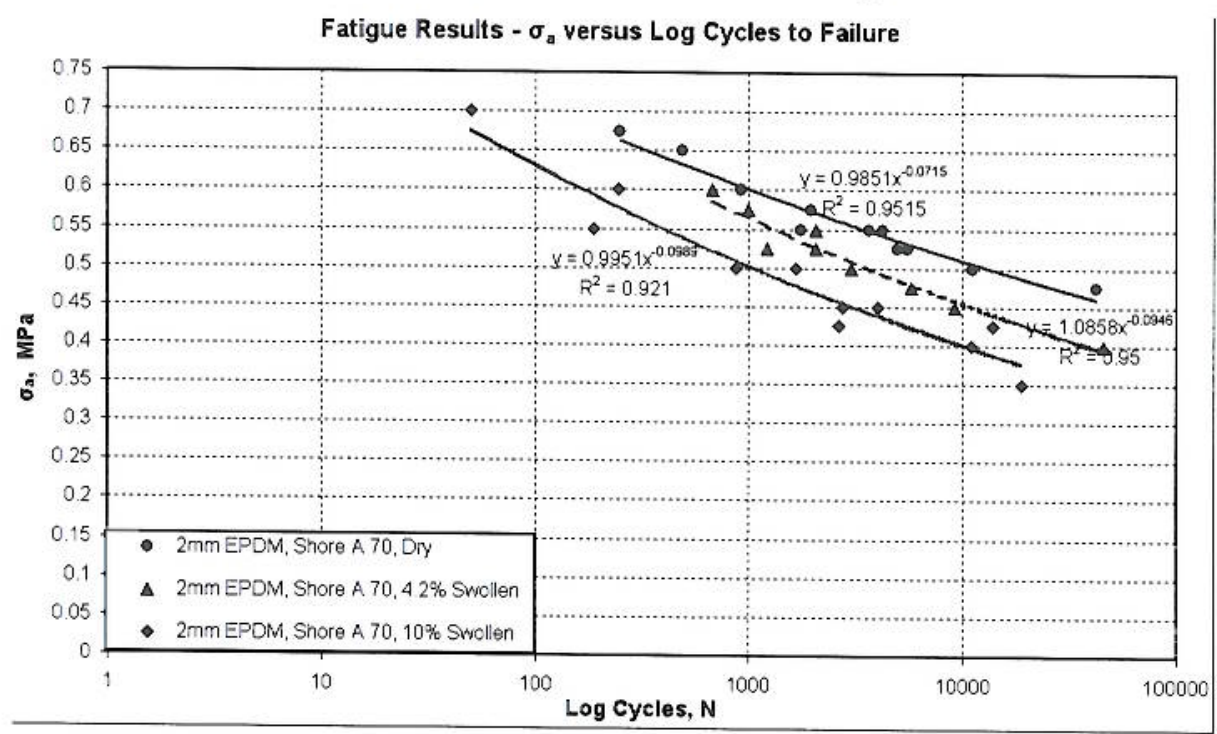

FIG. 3.- Plot of stress amplitude and cycles to failure for the dry and swollen specimens.

Unsurprisingly, the unswollen specimens exhibited greater fatigue resistance by comparison 
with the swollen test-pieces. It was clear that the fatigue life of the EPDM was reduced in proportion to the degree of swelling.

\section{CHANGES IN COMPLEX ELASTIC MODULUS, E*}

The fatigue behavior of the three specimen sets was subsequently analyzed with respect to the complex elastic modulus, $\mathrm{E}^{*}$, where $\mathrm{E}^{*}$ was determined from the slope of the loading curve from zero stress and minimum strain to peak engineering stress and maximum strain for the cycle in question. Plots of the decrease in modulus $\mathrm{E}^{*}$ with cycling of the test-piece for a stress amplitude of $\sigma_{\mathrm{a}}=1 \mathrm{MPa}$ for the three sample sets are shown in Figure 4.

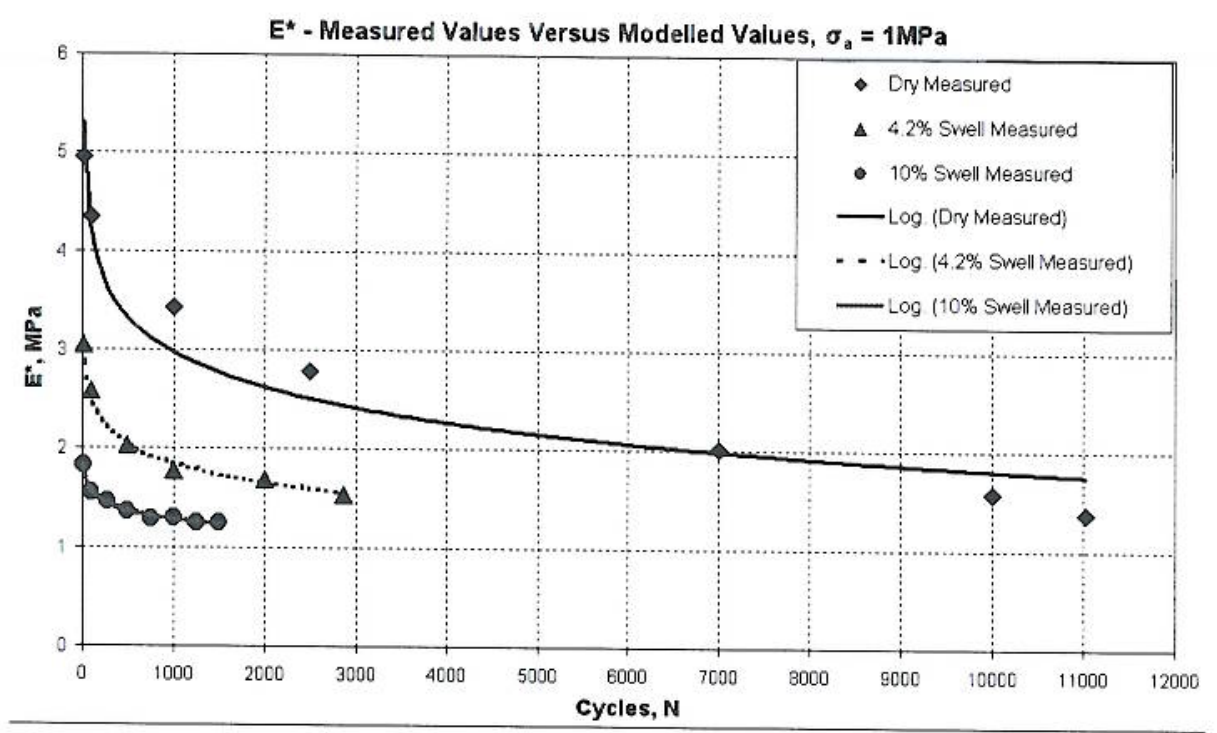

FIG. 4.- E* versus cycles $\mathrm{N}$ for dry, $4.2 \%$ and $10 \%$ swollen specimens at $\sigma_{\mathrm{a}}=1 \mathrm{MPa}$.

In tests carried out by Abraham, ${ }^{15}$ it was found that for a given material, failure consistently occurred after a specific loss in complex modulus $\mathrm{E}^{*}$. This predictor, termed $\mathrm{E}_{\text {residual }}$ can be represented as:

$$
E_{\text {residual }}^{*}=\frac{E^{*}}{E_{\text {conditioning }}^{*}} \cdot 100 \%
$$

This value of $\mathrm{E}_{\text {residual }}^{*}$ is quoted as a percentage and appeared to be independent of the applied loading. The dry and swollen specimens were analyzed using this approach, where the $\%$ value of $\mathrm{E}^{*}{ }_{\text {residual }}$ versus cycles was plotted up to $95 \%$ of the fatigue life of the specimen. $\mathrm{E}_{\text {conditioning }}^{*}$ was defined as the modulus of the material after ten conditioning cycles. The plot of decrease in $\mathrm{E}^{*}$ residual is shown for the dry EPDM in Figure 5. $\mathrm{E}^{*}$ residual was found to have an average value of $33 \% \pm 10 \%$ of its original value at $95 \%$ of the fatigue life of each dry specimen. The $4.2 \%$ and $10 \%$ swollen specimens had values of $\mathrm{E}^{*}$ residual of $50.5 \% \pm 10 \%$ and $60.1 \% \pm 5 \%$ at $95 \%$ of specimen life, respectively. 


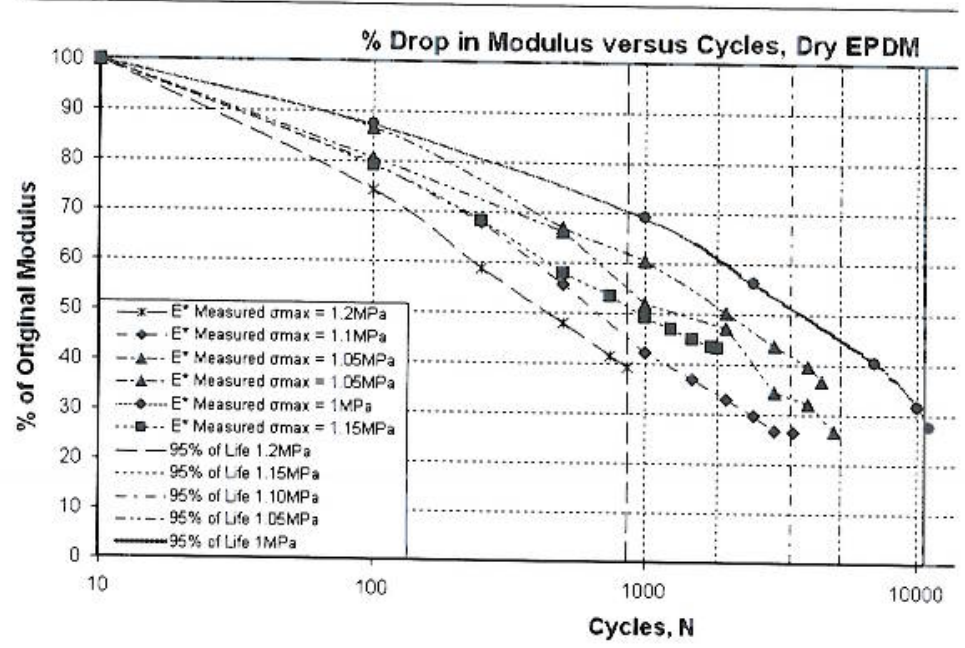

FIG. 5.- $E_{\text {residual }}^{*}$ versus $\log$ cycles, $N$ for dry EPDM at five different stress amplitudes.

TABLE II

E* $_{\text {RESIDLAL }}$ AT $95 \%$ OF SPECIMEN LIFE

\begin{tabular}{cc}
\hline Degree of Swell & E*Residual at 95\% of specimen Life \\
\hline Dry & $33 \% \pm 10 \%$ \\
\hline $4.2 \%$ Swell & $50.5 \% \pm 10 \%$ \\
\hline $10 \%$ Swell & $60.1 \% \pm 5 \%$ \\
\hline
\end{tabular}

CORRELATION BETWEEN DRY AND SWOLLEN MODULI

The dry and $4.2 \%$ swell specimen sets were compared at similar stress amplitudes, where the $100 \%$ initial modulus value $\left(\mathrm{E}^{*}\right.$ conditioning ) for both sets of specimens was taken as the value at ten conditioning cycles in the dry specimens, for each respective stress amplitude. The trends for each specimen set are shown for five stress amplitudes in Figure 6.

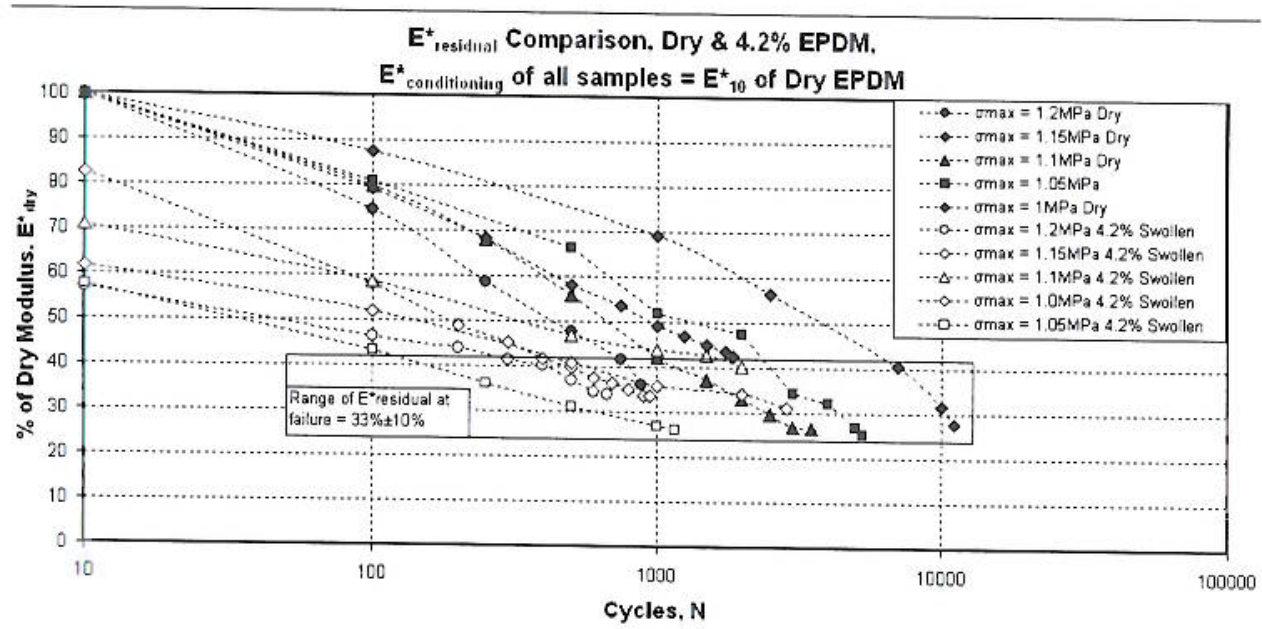

FIG. 6. $-\mathrm{E}^{*}$ residual versus $\log$ cycles, $\mathrm{N}$ for dry and $4.2 \%$ swollen EPDM at five different stress amplitudes. 
There is an average $\mathrm{E}^{*}$ residual at failure of $33 \% \pm 10 \%$ for these sets of specimens, at the four different stress ranges. By knowing the initial modulus $\left(\mathrm{E}^{*}{ }_{\text {conditioning }}\right.$ ) for the dry specimens, an approximation of the failure modulus for the swollen test-pieces can be determined.

When comparing the three specimen sets at similar stress amplitudes, the number of samples which could be analyzed was limited, due to the $10 \%$ swollen specimens having short lives at higher stress amplitudes and the dry specimens having extremely long fatigue lives at lower stress amplitudes, with many of these tests typically ending with failures at the clamp edge. However, for a stress amplitude of $1 \mathrm{MPa}$, comparison can be made between all three sample sets in terms of the decrease in specific modulus. Analysis of the value to which $\mathrm{E}_{\text {residual }}$ decreases for each sample type at a stress amplitude of $\sigma_{\mathrm{a}}=1 \mathrm{MPa}$, with $\mathrm{E}^{*}$ conditioning taken as the modulus of the dry EPDM after ten conditioning cycles, suggested that $\mathrm{E}^{*}{ }_{\text {residual }}$ fell within the $33 \% \pm 10 \%$ range at failure for each of the three specimens.

\section{CHANGES IN DYNAMIC STORED ENERGY}

Previous analysis of uniaxial test data on EPDM found good correlation between the dynamic stored energy in the specimen versus the cycles at failure and proposed its use as a plausible fatigue life predictor. ${ }^{15,16}$ The dynamic stored energy is defined as the area bounded by the unloading portion of the stress-strain curve during a measurement cycle, where the energy was quoted in units of $\mathrm{Nmm}$. Figure 7 shows how the dynamic stored energy was calculated from the stress-strain data.

The results for the fatigued specimens presented in this work were also analyzed with respect to the dynamic stored energy.

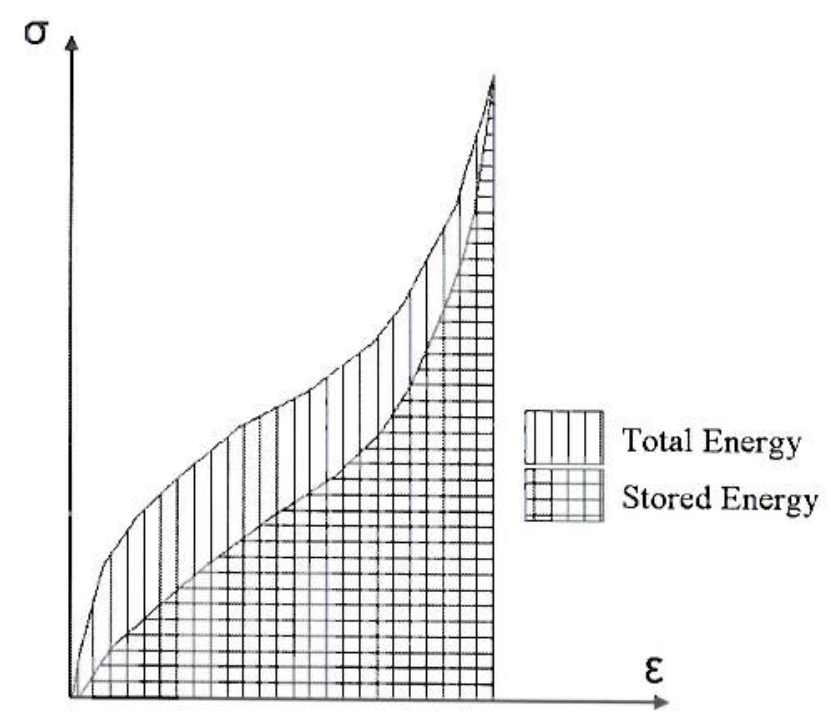

FIG. 7.- Calculation of total and stored energy for a cyclic stress-strain curve.

During equi-biaxial fatigue testing, a number of stress-strain measurements were made at intervals throughout the test. The dynamic stored energy in a cycle was subsequently calculated for these measured cycles. When plotted against the cycles to failure, the dynamic stored energy was found to increase linearly following conditioning of the test-piece. Figure 8 shows the plot of dynamic stored energy for the dry EPDM specimens. Similar plots were generated for the $4.2 \%$ and $10 \%$ swollen EPDM. The three plots are shown together in Figure 9.

At similar stress amplitudes, the dry EPDM samples had higher dynamic stored energy at 
failure than the swollen specimens, with the $10 \%$ swollen rubber having the lowest dynamic stored energy for a given stress amplitude. This result is due to the stiffness of the specimen decreasing with greater swelling. This is accompanied by a consequent increase in stored energy in a sample for a constant magnitude of stress amplitude. This is consistent with the simple relationship between energy and stiffness given by Equation (5):

$$
W=\frac{1}{2} \frac{F^{2}}{k}
$$

Where $\mathrm{W}$ is strain energy, $\mathrm{F}$ is the applied load and $\mathrm{k}$ is the stiffness of the material.

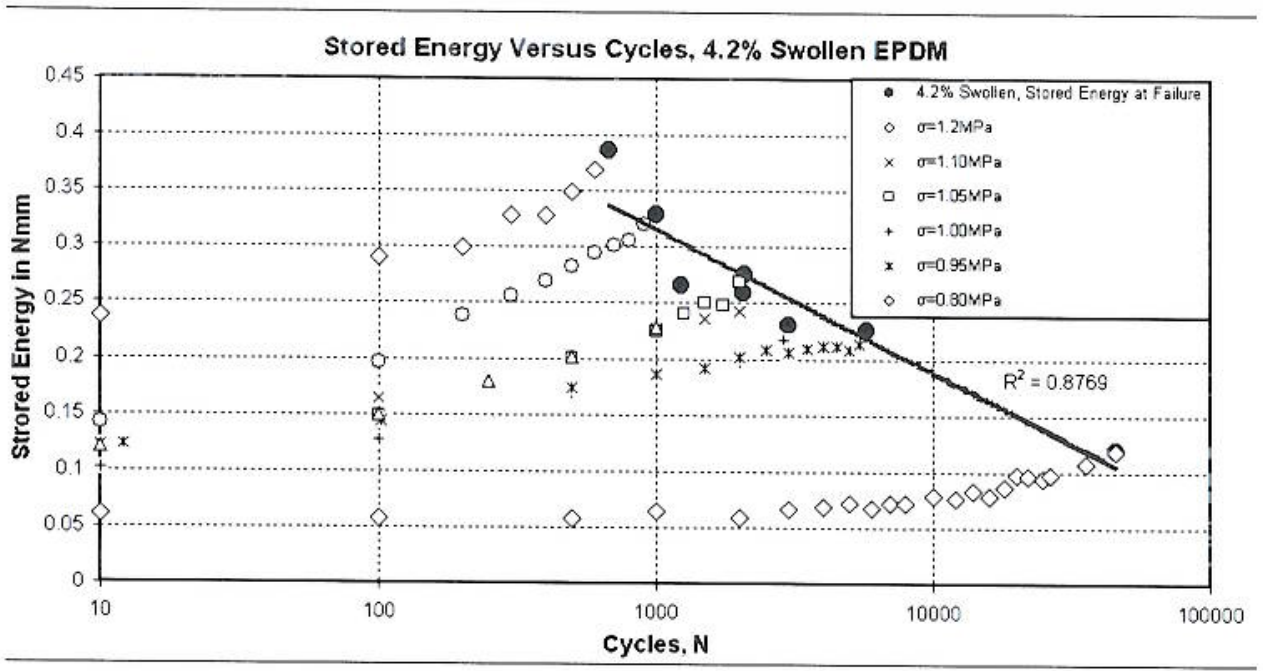

FIG. 8.- Plot of Dynamic Stored Energy for the 4.2\% Swollen EPDM at several stress amplitudes.

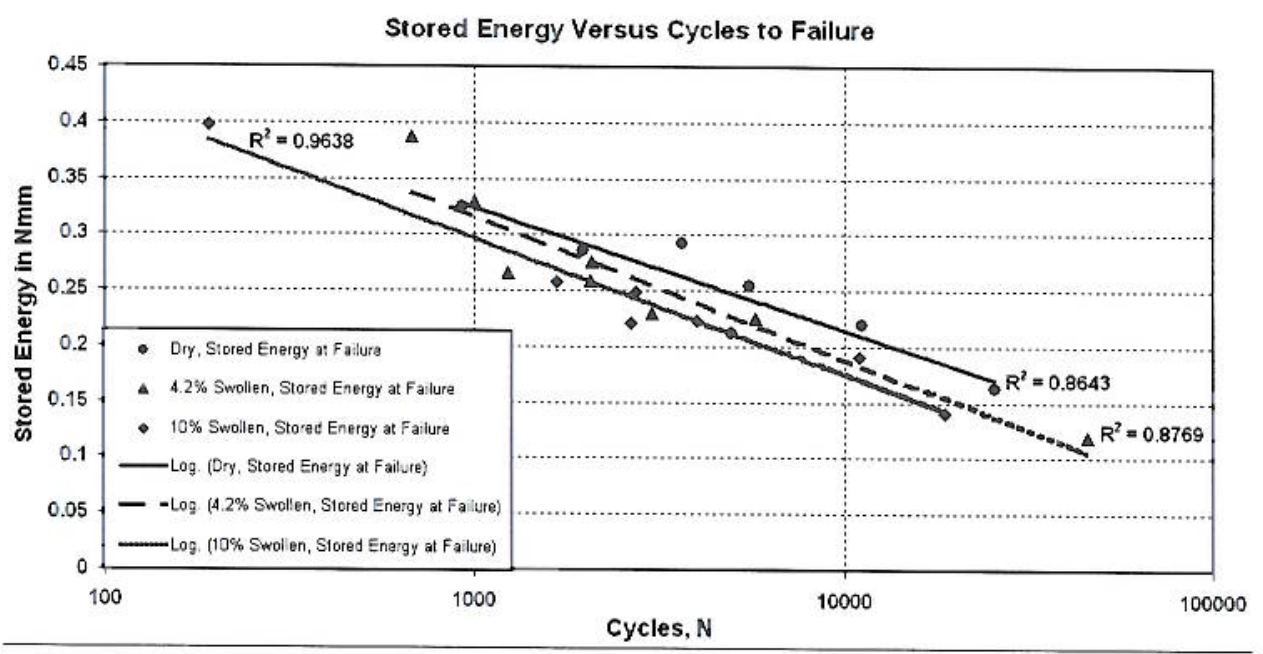

FiG. 9.- Plot of Dynamic Stored Energy versus log cycles to failure for the three specimen sets. 


\section{SURFACE MORPHOLOGY AT FAILURE}

The fracture surfaces of the dry samples were analyzed using a scanning electron microscope. A magnification factor of $\mathrm{X} 400$ at $2.0 \mathrm{kV}$ was used to view failure surfaces. For low cycle lives of less than one hundred, the type of failure is more akin to that of a single cycle test to destruction, with the surface morphology fibrous in nature and in some instances showing delamination at the failure surface. Failures at cycles greater than this show clear evidence of crack propagation and subsequent rupture. In most fatigue failures, cracks predominately propagated in the bubble pole region. Failure was deemed to have occurred when rupture took place at these crack sites. This behavior was common to both the dry and swollen specimens. SEM images of the surface morphologies of the specimens at a similar stress amplitude of $1 \mathrm{MPa}$ are shown in Figure 10. In the dry samples there is a coarser failure surface at lower cycles than for failures at higher cycles. Fatigue tests carried out elsewhere reported that the surface of the dry samples indicated blunt tearing, while the surfaces of the swollen test-pieces indicated sharp tearing. ${ }^{2}$

This was confirmed by the SEM images taken in this study, where the blunter surface of the dry specimens can be contrasted with the smoother surface of the swollen test-pieces. This blunt tearing could be attributed to more polymer filler interaction in the dry material, with the material being tougher for a given applied stress. The SEM imaging suggests that the swollen failure surfaces 'flow' more easily over one another than those of the dryer specimens.
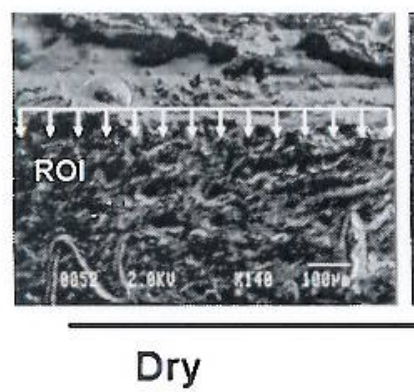

$$
\sigma_{\mathrm{a}}=1 \mathrm{MPa}
$$

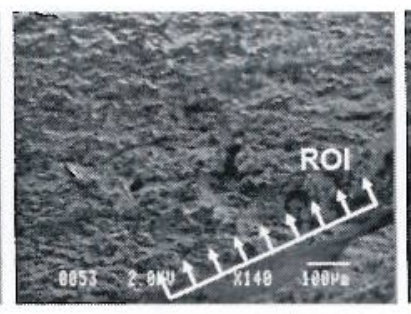

$4.2 \%$ Swollen

$$
\sigma_{\mathrm{a}}=1 \mathrm{MPa}
$$

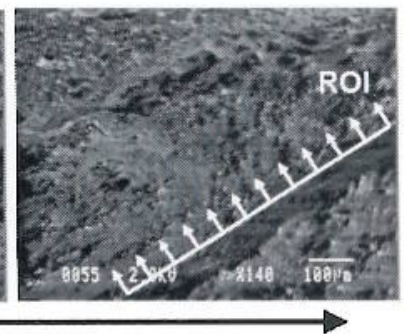

$10 \%$ Swollen

$$
\sigma_{\mathrm{a}}=1 \mathrm{MPa}
$$

FIG. 10. - SEM Imaging of specimen fracture surfaces, $\sigma_{\text {eng }}=1 \mathrm{MPa}(\mathrm{ROI}=$ Region of interest $)$.

It can be seen that flaws are more abundant in the swollen material, which can be attributed to the swelling effects of the oil. Due to the presence of these flaws the probability of crack growth being initiated at these flaws would be expected to be high, as the areas around the flaws would potentially have a lower complex modulus than other points in the network.

\section{DISCUSSION}

It was found that the fatigue life results produced in the equi-biaxial tests agreed with those for the dynamic uniaxial load case; that is, the fatigue life of the specimens was reduced in proportion to the amount of swelling.

The relationship between dynamic stored energy and cycles to failure is influenced by the degree of swelling of the test-pieces, with the energy at failure reducing for increases in swelling levels. It may be possible to relate the swollen predictor curve to the dry predictor curve by using some offsetting factor similar to those determined by Ronan $e t$ al. to predict long-term stress relaxation in elastomers. ${ }^{17}$

A more practical approach to predicting realistic fatigue lives in rubber compounds may be to use the limiting value of the residual modulus $\mathrm{E}_{\text {residual. }}^{*}$. When the residual modulus for 
swollen specimens is based on a calculation using the initial conditioned modulus of the dry rubber at a similar stress amplitude, $\mathrm{E}_{\text {residual }}^{*}$ values exhibited reasonable correlation, with a limiting value of $33 \% \pm 10 \%$ for both the dry and swollen specimens. By knowing the limiting value of $\mathrm{E}^{*}$ residual, the effect of swelling on fatigue life can be calculated, if the value of $\mathrm{E}^{*}{ }_{\text {conditioning }}$ is known at a particular stress amplitude.

This approach could have practical significance in the design of elastomeric components subjected to fatigue loading conditions. Consider a component manufactured from a similar compound to that used in these tests. If the part was loaded within a constant engineering stress range and the value of $\mathrm{E}^{*}$ conditioning at that stress range known, it could be proposed that once the value of $\mathrm{E}^{*}$ residual fell below a material specific value of $43 \%$ then replacement of the part should be considered.

\section{CONCLUSION}

In summary, the fatigue life of an EPDM sample under dynamic equi-biaxial loading can be greatly reduced in the presence of an oil in the rubber network, even for relatively small amounts of swelling. Despite being in contact with the oil for only one hour at $100^{\circ} \mathrm{C}$, the dynamic properties such as the complex modulus $\mathrm{E}^{*}$ and the dynamic stored energy are fundamentally altered from those of untreated EPDM. The changes in these properties and the lower fatigue lives of the swollen specimens can be attributed to a number of factors, both physical and chemical in nature.

Physical factors include the presence of larger voids in the network and a lower initial complex modulus due to the swelling action. The presence of these flaws in the elastomer network structure was confirmed by SEM imaging, which showed that the failure surfaces for each set of test-pieces is markedly different in the dry and swollen cases.

Chemical factors which may explain the difference in the dynamic mechanical properties of the unswollen specimens include changes in the network structure due to oil swelling, where there may be a reduction in the number of cross-links resisting the tensile force or where the swelling may lead to differences in the equilibrium length of individual chains. Also, it has been reported elsewhere that the reformation of polysulphidic linkages during a loading cycle can be inhibited in the presence of oil. ${ }^{3}$

The practical significance of this study is to highlight the effect of contamination on the mechanical performance of non-strain crystallizing elastomers subjected to realistic loading conditions. EPDM components are commonly used in automotive applications, where they provide the advantage of having more functionality at higher temperatures than SBR or natural rubber. However, some of these advantages are offset by their poor resistance to the numerous fluids used in vehicles. The results presented here illustrate that if a risk of oil contamination is sufficiently high and the automotive design engineer has failed to fully take swelling into account, safety factors and life expectations may be unrealistically high and components will lack the residual mechanical strength to withstand levels of fatigue loading.

\section{ACKNOWLEDGEMENT}

The authors would like to thank the Faculty of Engineering and the Directorate of Research and Enterprise in the Dublin Institute of Technology. This work was made possible by funding from Enterprise Ireland under its 'Proof of Concept' program.

\section{REFERENCES}

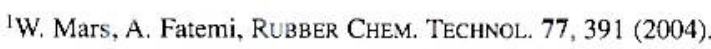

${ }^{2}$ P. J. Flory, J. Rehner, J. Chem. Phys. 11, 521 (1943). 


\section{EQUI-BIAXIAL FATIGUE OF ELASTOMERS-THE EFFECT OF OIL SWELLING 649}

${ }^{3}$ K. Cho, J. J. Wook, L. Daeho, C. Hyunaee, C. Young-Wook, Polymer. 41, $179(2000)$.

${ }^{4}$ V. Gul, D. Fedyukin, B. A. Dogadkin, Rubber Chem. Technol. 32, 454 (1959).

${ }^{5}$ B. A. Dogadkin, V. Gul, Rubber Chem. Technol. 24, 344 (1951).

${ }^{6}$ C. Neogi, A.K. Bhattacharya, A.K. Bhowmick, Rubber Chem. Technol. 63, 651 (1990).

${ }^{7}$ P. Abhimanyu, T. Coolbaugh, RuBber CHEM. TECHnOL. 78, 516 (2005).

${ }^{8}$ A. Beerbower, D. A. Pattison, G. D. Staffin, Rubber Chem. Technol, 37, 246 (1964).

${ }^{9}$ ASTM Standard D471-95, "Standard Test Method for Rubber Property-Effect of Liquids," Annu. Book ASTM Stand. $09.01,86$ (1995).

${ }^{10} \mathrm{~N}$. Murphy, J. Hanley, J. McCartin, B. Lanigan, S. McLoughlin, S. Jerrams, G. Clauss, R. Johannknecht, "Determining multiaxial fatigue in elastomers using bubble inflation," in Constitutive Models for Rubber IV; P. E. Austrell, L. Kari, Ed.; Balkema, 2005; Vol, 4; p. 65-70.

"N. Murphy, J. Hanley, H. Ali, S. Jerrams, "The Effect of Specimen Geometry on the Multiaxial Deformation of Elastomers,". In Constitutive Models for Rubber V; A. Boukamel, L. Laiarinandrasana, S. Méo, E. Verron, Taylor \& Francis, 2007; Vol. 5; p. 61-65.

${ }^{12} \mathrm{~J}$. Hanley, Ph.D, thesis, Dublin Institute of Technology, Dublin, Ireland, 2008.

${ }^{13}$ R. Johannknecht, S. Jerrams, G. Clauss, J. Mater. Des. Applicat. 216, 233 (2002).

${ }^{14}$ R. Seldén, Progr. Rubber Plast Technol 11, 56 (1995).

${ }^{15} \mathrm{~F}$. Abraham, "The influence of minimum stress on the fatigue life of non strain-crystallizing elastomers," Ph.D. thesis, Coventry University, Coventry, United Kingdom, 2002.

${ }^{16}$ T. Alshuth, F. Abraham, S. Jerrams, RubBer CHEM. TECHNol. 75, 365 (2002).

${ }^{17}$ S. Ronan, T. Alshuth, S. Jerrams, N. Murphy, Mater. Des., 28, 1513 (2007). 